\title{
CONCEPÇÃO INTERATIVA E PARAMETRIZADA DE EDIFÍCIOS DE MÚLTIPLOS PAVIMENTOOS/EM CONCRETO ARMADO
}

INTERACTIVE AND PARAMETERIZED DESIGN OF MULTI-FLOOR BUILDINGS IN REINFORCED CONCRETE

\section{Felipe Tavares da Silva'}

RESUMO: O uso dos algoritmos generativos vêm crescendo bastante sobretudo agora com a maior popularidade das ferramentas de programação visual. A geração automática de componentes de uma edificação aliada à parametrização permite uma significativa melhora na procura de soluções ótimas e mais adequadas durante o processo de projeto. Propõe-se neste artigo a parametrização e criação de algoritmos generativos de estruturas de edificações porticadas de múltiplos pavimentos em concreto armado. Para isto, foram desenvolvidas expressões matemáticas de pré-dimensionamento com base nos critérios dos Estados Limites e em expressões analíticas simplificadas. Estas equações de prédimensionamento foram implementadas na ferramenta digital Grasshopper, sendo os resultados validados pelo sistema de cálculo e detalhamento estrutural TQS. Este algoritmo paramétrico de geração de estruturas porticadas tem por objetivo auxiliar o processo de concepção e projeto, oferecendo ao projetista em tempo real as dimensões da estrutura, o modelo tridimensional e a taxa de consumo de concreto. O algoritmo proposto também pode ser utilizado como instrumento de aprendizagem no estudo de sistemas estruturais porticados de múltiplos pavimentos em concreto armado.

PALAVRAS-CHAVE: Algoritmo generativo. Estruturas. Concreto Armado. Projeto. Pré-

dimensionamento

ABSTRACT: The use of generative algorithms has been growing quite specially now with the greatest popularity of visual programming tools. Automatic generation of components combined with building parameterization allows a significant improvement in the search for optimal and more appropriate solutions during the design process. It is proposed in this article a parametric generative algorithm for reinforced concrete framed structures buildings of multiple floors. For this, mathematical expressions of preliminary design based on the criteria of Limits States and simplified analytical expressions were developed. These pre-sizing equations were implemented in Grasshopper digital tool and the results validated by TQS Structural Analysis and reinforcement detailing. The parametric generation algorithm of these types of structure aims to help the process of conception and design, offering the designer in real time the dimensions of the structure, the three-dimensional model and the concrete consumption ratio. The proposed algorithm can also be used as a learning tool in the study of reinforced concrete structural framed systems with multiple floors.

KEYWORDS: Generative algorithm. Structures. Reinforced Concrete. Design.Preliminary design. 


\section{INTRODUÇÃO}

O processo de projeto de uma edificação arquitetônica é composta de várias etapas e engloba uma série de especialidades de áreas distintas. Uma destas etapas é a concepção e projeto estrutural. Este artigo propõe uma metodologia de concepção e pré-dimensionamento estrutural mais precisa e com visualização do resultado tridimensional em tempo real.

Segundo Macdonald (1998), desde o Movimento Renascentista ocorreu um distanciamento do trabalho técnico nos projetos de edificações. Isto poderia explicar a variedade de opiniões acerca de como deveria ser o processo da concepção estrutural para arquitetura, sobretudo em relação quando a estrutura deve ser concebida. Este mesmo autor propôs a idéia de classificar a relação entre arquitetura e estrutura em categorias: Estrutura Aceita e Estrutura Ignorada. Na categoria Estrutura Aceita tem-se as subcategorias Estrutura sendo Geradora de Formas e Estrutura sendo Arquitetura. Quando a estrutura é a geradora da forma arquitetônica, pode-se pensar em uma estrutura modular e de alta eficiência como é o caso de algumas construções porticadas, edifícios de cobertura de grandes vãos ou pontes.

Segundo esta linha de pensamento sobre o projeto da edificação, não há uma única forma de se conceber a estrutura de uma edificação. Ou seja, a melhor concepção estrutural, poderia se dizer que é aquela que melhor se adéqua aos demais sistemas prediais e que apresenta maior eficiência estrutural. Entende-se por eficiência estrutural como a razão entre as sobrecargas atuantes e as cargas totais sobre uma estrutura, sendo esta última o somatório do peso próprio com as sobrecargas estruturais (SANDAKER,2008). Assim, quanto menor o peso próprio da estrutura para suportar a mesma sobrecarga, mais eficiente esta será.

Tradicionalmente, independente de qual regra seja considerada para gerar o arranjo estrutural, utilizam-se ábacos ou percentuais da razão entre espessura e vão de um dado sistema estrutural para se obter as espessuras das peças estruturais. Rebello (2007) propõe percentuais e ábacos traduzidos de Corkill (1969). Vários outros autores (MACDONALD,1998; ENGEL, 2001; ALLEN e IANO,2002; REBELO,2007; CHING et. al.,2010) também lançam propostas de pré-dimensionamento de sistemas estruturais com base em valores relativos, percentuais ou ábacos.

Contudo, esta metodologia com a utilização de ábacos é muito mais eficaz para os primeiros passos do aprendiz no tema ou quando deseja-se ter um panorama global sobre um determinado sistema estrutural, sendo bastante imprecisa para efetuar pré-dimensionamentos em alguns casos. Um pré-dimensionamento impreciso pode gerar muitos ciclos retrógrados no processo de projeto, gerando assim retrabalho desnecessariamente.

Estas imprecisões são devidas desde a consideração apenas do elemento estrutural e não do sistema completo ou da não consideração da relação entre os diversos sistemas que compõem um layout estrutural. A não especificação precisa da magnitude das cargas ou das resistências do material estrutural também são lacunas encontrada no uso dos ábacos ou percentuais de pré-dimensionamento de estruturas.

$\mathrm{O}$ uso de algoritmos generativos paramétricos vem a auxiliar o projetista a encontrar a melhor conjuntura de parâmetros de modo a obter o resultado que melhor atenda aos requisitos de projeto. Estes requisitos geralmente são aspectos econômicos, de impacto ambiental, estéticos, funcionais, construtivos, dentre muitos outros.

Khabazi (2012) diz que o uso de algoritmos generativos no processo de projeto de edificações capta vários tipos de informações como parâmetros de entrada e produz geometrias como dado de saída. Esta tarefa só é prática se for realizada em ambiente computacional. Kolarevic (2003) advoga que os processo de geração digital da forma do objeto arquitetônico está abrindo novos espaços na investigação sobre a forma, saindo de uma conceituação de produção arbitrária da forma para uma conceituação de pesquisa e obtenção da forma, geralmente a partir de índices de desempenho.

Propõe-se neste artigo uma série de formulações que se referem a uma estrutura porticada em concreto armado formada por lajes maciças bidirecionais, apoiando-se em vigas e subseqüentemente em pilares, imersa em 
um contexto modular e paramétrico. Esta formulação foi posteriormente considerada em um algoritmo generativo de pórticos paramétricos, levando em consideração as dimensões dos módulos porticados, as dimensões das seções transversais, as classes de resistências do concreto e o nível de cargas envolvido no sistema. Este algoritmo generativo foi implementado no ambiente do plugin de programação visual Grasshopper com visualização geométrica 3D simultânea no ambiente do software CAD Rhinoceros.

Este conjunto composto por algoritmo generativo paramétrico aliado à visualização em tempo real do modelo estrutural tridimensional pode ser utilizado como instrumento de concepção estrutural deste tipo de sistema, verificando em tempo real as relações entre vão do sistema estrutural e as espessuras de suas peças. Além do pré-dimensionamento automático, de forma aproximada é possível também obter as taxas de consumo de concreto e conseqüentemente acessar o grau do impacto econômico e ambiental de cada contexto desejado.

Oliveira et al. (2013) obtiveram indicadores de consumo de materiais para edifícios em concreto armado entre 6 e 18 pavimentos, com lajes maciças em concreto armado e área de planta entre $260 \mathrm{~m}$ a $900 \mathrm{~m} 2$. Estes autores relataram que as taxas de consumo para sistemas de piso com lajes maciças e nervuradas apoiadas em vigas e do tipo cogumelo com vãos entre 4,0 $\mathrm{m}$ e 5,5 m, geraram valores da taxa de concreto entre 0,15 e 0,21 m2/m2 e taxa de aço ente 8,49 e 19,89 Kg/m2. Pereira et al. (2013), relataram índices de edificações entre 20 e 35 pavimentos em concreto armado, concebidos em lajes maciças e nervuradas, com áreas de planta entre 400 m2 e 1900 m2 e vãos entre 3,0 m e 4,8 m. Estes obtiveram valores de taxa de concreto entre 0,11 e 0,19 m2/m2 e taxas de armadura entre 6,59 e 12,65 Kg/m2. Estes índices de consumo de materiais serão tomados como referência para análise dos resultados obtidos pelo gerador de estruturas porticadas aqui proposto.

\section{Parametrização de sistemas de piso com lajes e vigas maciças em con- creto armado}

Em um processo de concepção e projeto de estruturas geralmente considera-se a seguinte seqüência de etapas: definição de um arranjo estrutural, pré-dimensionamento das espessuras das peças e construção de um modelo estrutural virtual para obtenção de esforços de projeto e deslocamentos estruturais. A partir deste modelo, verifica-se se as espessuras consideradas são suficientes para o atendimento das normas, sendo este processo geralmente chamado de dimensionamento. No caso de peças em concreto armado submetidas a esforços de flexão, ainda é parte do dimensionamento determinar a quantidade e posicionamento das armaduras.

Caso o pré-dimensionamento seja insuficiente, o processo de dimensionamento estrutural fará ciclos retroalimentados, alterando as espessuras estruturais até satisfazer as condições dos Estados Limites. Assim, um pré-dimensionamento mais eficiente é aquele que proporcionará ao processo de dimensionamento um número mínimo de ciclos, gerando espessuras estruturais que atendam as condições de capacidade resistente da estrutura e que garanta que a mesma não apresente deslocamentos excessivos durante o seu serviço.

Partindo deste entendimento, propõe-se um procedimento de pré-dimensionamento estrutural a partir da associação de soluções analíticas de esforços e deslocamentos máximos estruturais às condições do Estado Limite Último (ELU) e do Estado Limite de Serviço (ELS). O ELU é evitado quando as solicitações de projeto são inferiores às resistências de projeto ( $\mathrm{Sd} \leq \mathrm{Rd})$ e o ELS para deslocamentos é evitado quando os deslocamentos máximos estruturais são inferiores aos deslocamentos admissíveis ( $\delta$ MAX $\leq \delta \mathrm{ADM})$ preconizados por norma.

Considerando expressões analíticas da Mecânica Geral e das Resistências dos Materiais (CARVALHO e PINHEIRO,2013) obtém-se as solicitações de projeto e os deslocamentos máximos, onde estas são dadas em função do nível de carga e do vão, seja para momentos fletores, esforços cortantes, esforços normais ou combinados. De acordo com a norma de estruturas em concreto armado brasileira (NBR6118,2003), obteve-se os esforços re- 
sistentes e os deslocamentos admissíveis, resultando em expressões que relacionam a dimensão da seção transversal da peça estrutural e a tensão resistente do concreto. Desta maneira, obtém-se expressões paramétricas que relacionam as dimensões estruturais de vão e espessuras com o nível de cargas e resistência característica do concreto.

Nas equações de 1 a 4 estão as expressões finais que fornecem o vão máximo de uma laje maciça bidirecional com painéis de lados iguais segundo as condições do Momento Fletor (LMF), Esforço cortante (LEC) e deslocamento (LDES).

$$
\begin{array}{ll}
L_{M F} \leq 0,36 \cdot d \cdot \sqrt{\frac{f_{c k}}{q_{L A J E}}} & L_{D E S 2} \leq 0,57 \cdot d \cdot\left(\frac{\sqrt{f_{c k}}}{q_{V A R}}\right)^{1 / 3} \\
L_{D E S 1} \leq 0,47 \cdot d \cdot\left(\frac{\sqrt{f_{c k}}}{q_{P P}+q_{R E V}+0,3 \cdot q_{V A R}}\right)^{1 / 3} & L_{E C} \leq 0,84 \cdot \frac{f_{c k}^{2 / 3} \cdot d}{q_{L A J E}}
\end{array}
$$

Nas equações acima, d é a espessura da laje maciça bidirecional em centímetros, fck é a resistência característica do concreto em MPa, $\mathrm{q}_{\mathrm{LAIE}}$ a carga total sobre a laje em $\mathrm{KN} / \mathrm{m}$, sendo $\mathrm{q}_{\mathrm{pp}}, \mathrm{q}_{\mathrm{REV}}$ e $\mathrm{q}_{\mathrm{VAR}}$ suas parcelas de peso próprio, peso de revestimento e carga variável, respectivamente.

A condição do momento fletor foi obtida considerando o momento negativo de uma laje bidirecional engastada em duas bordas e rotulada nas outras duas onde o momento resistente foi definido por uma zona comprimida de 30\% da seção transversal da laje (NBR6118,2003). Para o esforço cortante foi considerado como condição limitante o Cortante Resistente que prescinde armadura para este esforço, visto que geralmente não se considera armadura para este tipo de esforço em lajes maciças sobre vigas. Para o deslocamento foi considerado o critério definido por Carvalho e Pinheiro (2013), considerando apenas 30\% da carga variável somada com a carga permanente na comparação do deslocamento admissível de L/250 e considerando apenas a carga variável na comparação com o deslocamento admissível de L/350. 0 vão máximo da laje será o menor dentre todos estes vãos máximos, uma vez que o menor destes satisfaria a todas estas condições limitantes de esforços e deslocamentos atuantes. Considerando um edifício porticado com lajes bidirecionais de iguais dimensões do painel, o vão definido para a laje é o mesmo para as vigas. Com isto, aplicando as condições dos Estados Limites às vigas de forma semelhante como foi feito às lajes, determinam-se alturas mínimas das vigas de alma cheia de acordo com os fatores limitantes de esforços e deslocamentos atuantes.

$h_{V_{-} M F} \geq \frac{7 \cdot b_{V} \cdot L v^{2}+1,6 \cdot \sqrt{19,14 \cdot b_{V}{ }^{2} \cdot L v^{4}+7 \cdot 10^{7} \cdot C_{M} \cdot b_{V} \cdot L v^{2} \cdot f_{c k} \cdot\left(n \cdot R_{L A J E}+q_{A L V}\right)}}{32000 \cdot C_{M} \cdot b_{V} \cdot f_{c k}}$

$$
C_{M}=\left\{\begin{array}{l}
0,0001946 \rightarrow f c k \leq 35 \mathrm{MPa} \\
0,0001638 \rightarrow f c k>35 \mathrm{MPa}
\end{array}\right.
$$


$h_{V_{-} E C} \geq \frac{0,875 \cdot L v \cdot\left(n \cdot R_{L A J E}+q_{A L V}\right)}{\left(0,019-0,000077 \cdot f_{c k}\right) \cdot f_{c k} \cdot b_{V}-0,0022 \cdot b_{V} \cdot L v}$

$h_{V_{-} D E S 1} \geq \sqrt[3]{a+\sqrt{a^{2}+b}}-\sqrt[3]{-a+\sqrt{a^{2}+b}}$

$\rightarrow\left\{\begin{array}{l}a=\frac{1277 \cdot L v^{3} \cdot\left(n \cdot\left(R_{L_{A J J} P_{P E R M}}+0,3 \cdot R_{L_{A J E_{-}} V A R}\right)+q_{A L V}\right)}{b_{V} \cdot \sqrt{f_{c k}}} \\ b=\frac{-9,7 \cdot L v^{9}}{\sqrt{f_{c k}{ }^{3}}}\end{array}\right.$

$h_{V_{-} D E S 2} \geq 11,27 \cdot L v \cdot\left(\frac{n \cdot R_{\text {LAJE_VAR }}}{b_{V} \cdot \sqrt{f_{c k}}}\right)^{1 / 3}$

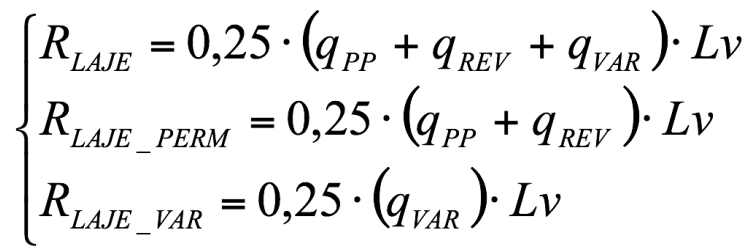

As equações de 5 a 10 fornecem as alturas mínimas das vigas em função da base da viga $b_{v}$ em centímetros, do vão da viga $L_{v}$ em metros, da resistência característica do concreto fck em MPa, da carga de alvenaria sobre a viga $\mathrm{q}_{\mathrm{ALV}}$ em $\mathrm{KN} / \mathrm{m}^{2}$ e da reação de $n$ lajes sobre a viga $\mathrm{R}_{\mathrm{LAIE}}$ dada em $\mathrm{KN} / \mathrm{m}$. A maior altura da viga dentre estas altura mínimas é a que prevalece sobre as demais pelo fato de ser esta a que satisfaz a todas as condições.

As duas condições de momento fletor para a viga são derivadas das limitações máximas da tensão na região comprimida da seção de concreto. Em relação ao esforço cortante, foi considerado a condição limite da biela comprimida, sendo a armadura de estribo a ser quantificada no processo posterior de dimensionamento e detalhamento das armaduras

Em peças estruturais em concreto armado submetidas a flexão, a altura da seção é definida pela limitação da região comprimida para garantir ductilidade (NBR6118,2003), quantificando e posicionando a armadura em etapa posterior no projeto estrutural.

Quando se tem várias expressões que relacionam as dimensões das peças e os vãos, pode-se realizar uma concepção estrutural a partir de um arranjo modular de uma unidade básica formada neste caso por 4 pilares, 4 vigas e uma laje. Moussavi (2009) advoga que os arranjos estruturais podem ser obtidos pelo conceito Bottom-Up, que poderia se traduzir como "de dentro para fora". Utilizando-se deste conceito de unidade básica estrutural e uma forma de replicação, esta autora propôs uma série de unidades básicas estruturais e variadas formas de replicá-las, gerando assim um grande número de possibilidades de arranjos estruturais para edificações arquitetônicas em várias tipologias de sistemas estruturais.

Nesta proposta de parametrização do sistema de piso, o tamanho do vão entre pilares será definido pela espessura da laje, definindo o vão máximo para as lajes e vigas, como ilustra a figura 1. 


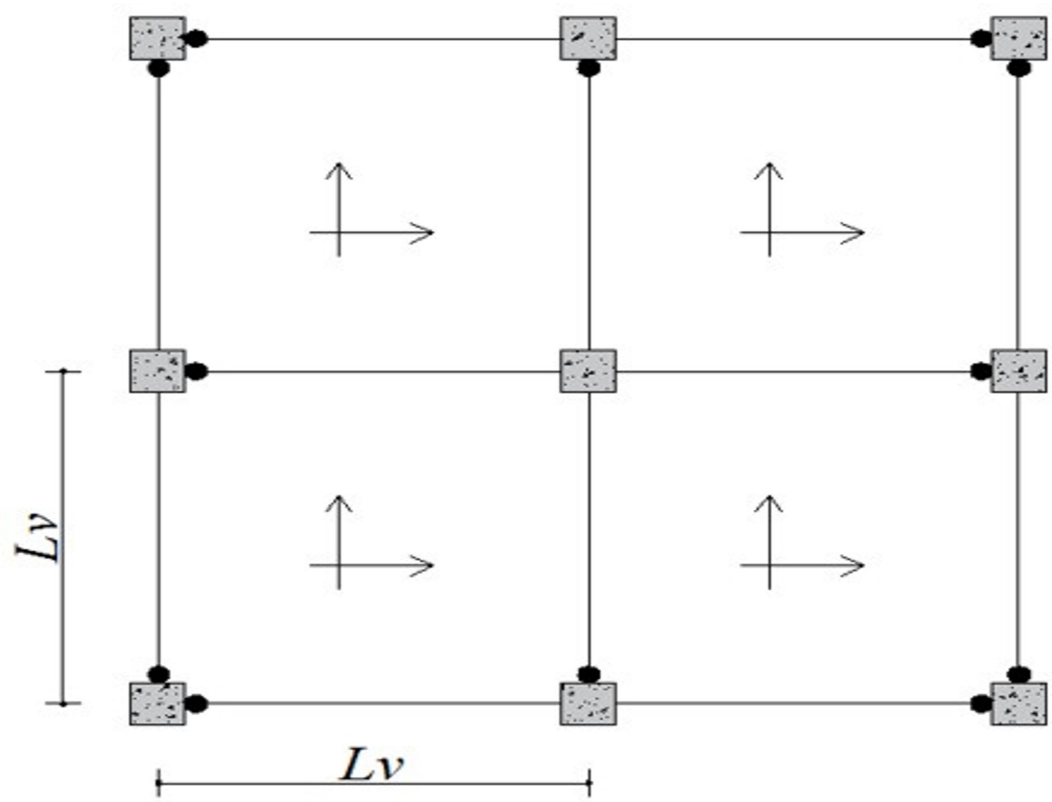

Dependendo da necessidade ou programa arquitetônico, pode-se replicar este sistema de piso nas duas direções horizontais, obtendo-se assim automaticamente um arranjo e modulação de pilares. Para que a formulação do sistema de piso proposta tenha coerência, deve-se conceber um sistema de piso que contenha pelo menos dois painéis de laje em cada direção de planta (figura 1) para que assim se obtenham vigas contínuas

\section{Parametrização de pórticos de nós rígidos e base engastada}

Analiticamente é possível obter de forma aproximada os deslocamentos laterais de um pórtico de múltiplos pavimentos (SCHULTZ,1992), estimar aproximadamente os esforços máximos de Momento Fletor, Esforço Cortante e Normal (HIBBELER,2012), tanto devido a cargas gravitacionais, quanto devido a carga de vento.

De maneira semelhante à parametrização dos pisos, propõe-se formulações paramétricas que definem o número máximo de pavimentos em função das dimensões do vão entre pilares, das distâncias entre pavimentos, das dimensões dos pilares, da resistência característica do concreto, da taxa de armadura dos pilares, dos parâmetros que definem a intensidade do vento e do nível de sobrecarga no sistema de piso.

A tipologia do sistema de contraventamento considerada nesta parametrização de edificação porticada foi a ligação rígida entre vigas e pilares que formam o pórtico. Portanto, para a parametrização dos pilares da estrutura do edifício, foram consideradas soluções analíticas de esforços e deslocamentos máximos e estas comparadas com os limites da norma nas situações críticas de projeto. Foram consideradas como situações críticas o controle do deslocamento lateral máximo no topo do edifício; a capacidade resistente do pilar no tramo mais inferior e a estabilidade global através do parâmetro $\gamma_{\text {z }}$. Estas situações foram consideradas para formações de pórticos nas duas direções ortogonais em planta, com consideração de pórticos com no mínimo três pilares.

Devido ao fato de que os pilares estão sujeitos prioritariamente a um estado de esforços de flexo-compressão, há uma dificuldade de se obter uma expressão analítica que relacione esta combinação de esforços às dimensões da estrutura e à resistência dos materiais simultaneamente.

No equacionamento da condição de capacidade resistente à flexo-compressão do pilar, foi considerada uma aproximação do diagrama clássico de interação entre o Momento Fletor e o Esforço Normal (WIGHT e MACGREGOR,2012; CARVALHO e PINHEIRO,2013) por um polinômio do segundo grau. Considerou-se nesta aproximação o eixo das abscissas como sendo o 
eixo do esforço normal de projeto $(\mathrm{Nd})$ e o das ordenadas como sendo o eixo do Momento Fletor de projeto (Md). Assim através da fixação dos parâmetros que definem o diagrama e a função do polinômio, determinou-se a equação simplificada de interação entre Md e Nd, dada pela equação 11.

$$
\begin{aligned}
& M_{d}=-A \cdot N_{d}^{2}+B \cdot N_{d}+C \\
& C=0,50 \cdot A_{s} \cdot E_{s} \cdot\left[0,0021 \cdot c o b^{2}+0,00052 \cdot h_{p}{ }^{2}+0.0039 \cdot h_{p}-0,000038 \cdot \frac{A_{s} \cdot E_{s}}{b w \cdot f_{c d}}-0,0021 \cdot c o b \cdot h_{p}\right] \\
& B=\frac{1,8 \cdot M_{d, b a l}-2 \cdot C+2 \cdot \sqrt{M_{d, b a l} \cdot\left(0,81 \cdot M_{d, b a l}-0,9 \cdot C\right)}}{0,95 \cdot N_{u}} \\
& A=\frac{B}{0,95 \cdot N_{u}}+\frac{C}{\left(0,95 \cdot N_{u}\right)^{2}}
\end{aligned}
$$

$$
\begin{aligned}
& N_{u}=0,85 \cdot b_{P} \cdot h_{P} \cdot f_{c d}+2 \cdot A_{S} \cdot f_{y d} \\
& M_{d, b a l}=b_{P} \cdot f_{c d}\left(0,1 \cdot h_{P}{ }^{2}-0,033 \cdot c o b \cdot h_{P}-0,067 \cdot c o b^{2}\right)+A_{S} \cdot\left(434782,61 \cdot h_{P}-869565,21 \cdot c o b\right)
\end{aligned}
$$

Nas equações de 12 a 16, tem-se as dimensões do pilar $b_{p}$ e $h_{p}$ e o cobrimento da armadura cob em metros; tensão resistente de projeto do concreto fcd, tensão de escoamento da armadura $\mathrm{f}_{\mathrm{yd}}$ e o módulo de elasticidade do aço $\mathrm{E}_{\mathrm{S}}$ em KN/m2; e a área de aço de uma das bordas das faces de maior esforço normal no pilar $\mathrm{A}_{\mathrm{s}}$ em $\mathrm{m} 2$. Na equação 15, a carga última do pilar Nu é dada em KN e representa o valor máximo para $\mathrm{Nd}$ onde o diagrama cruza o eixo das abscissas. Na equação 16, o Momento fletor da ruptura balanceada entre concreto e aço $\mathrm{M}_{\mathrm{d} \text {,bal }}$, dado em $\mathrm{KN}$.m, representa o ponto de máximo momento no diagrama original. Assim, o pico de máximo momento do diagrama aproximado deve estar também nesta ordem de valor.

Nesta formulação proposta, concebe-se uma área de aço $\mathrm{A}_{\mathrm{S}}$ simétrica nas duas faces de maior tensão normal em relação ao eixo de flexão, paralelo à dimensão da base do pilar $\mathrm{b}_{\mathrm{p}}$. Esta área de aço AS foi considerada em apenas uma única camada e faceando as arestas de dimensões $b_{p}$. As dimensões do pilar $b_{p}$ e $h_{p}$ não são respectivamente e necessariamente a menor e a maior dimensão do pilar. Estas dimensões são a base e a altura de acordo com o eixo de flexão, como ilustra a figura 2. 


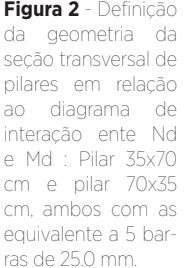

ras de $250 \mathrm{~mm}$.
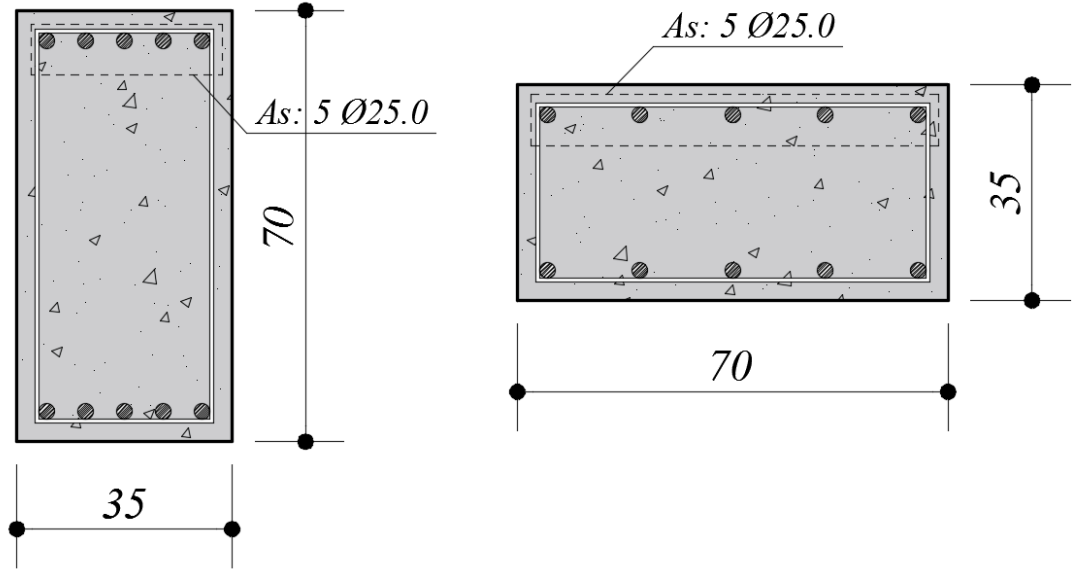

A região formada pelo gráfico da equação 11 e os eixos cartesianos delimita as situações em que um determinado pilar suporta uma combinação de esforços $\mathrm{Nd}$ e Md para suas dimensões de seção transversal bruta, taxa de aço e classe do concreto. Na figura 3 estão alguns exemplos de diagramas de interação entre o esforço normal de projeto $(\mathrm{Nd})$ e o momento fletor de projeto $(\mathrm{Md})$ de um pilar.

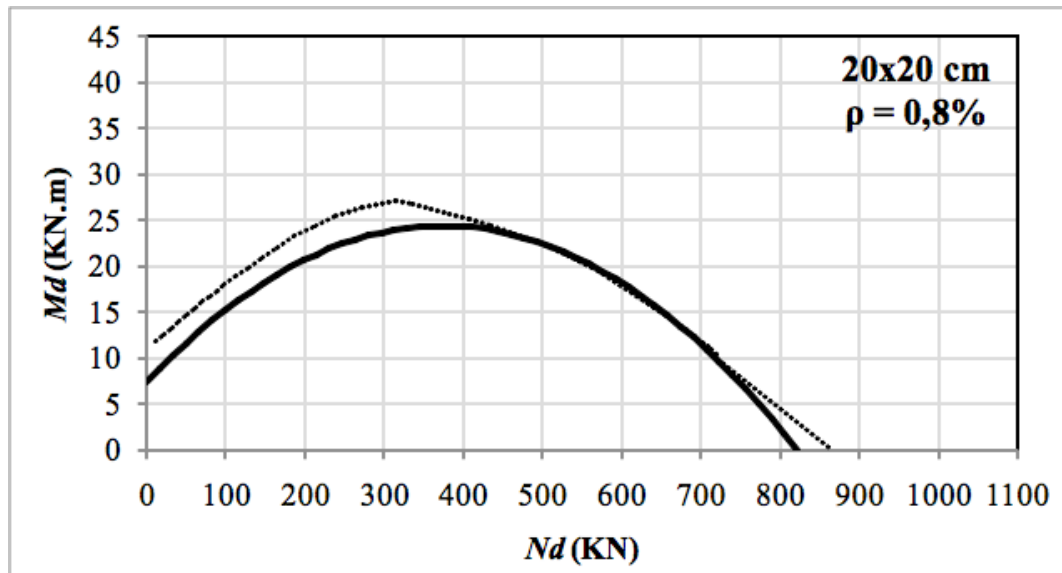

......... Diagrama Clássico (NBR6118) —Diagrama aproximado proposto

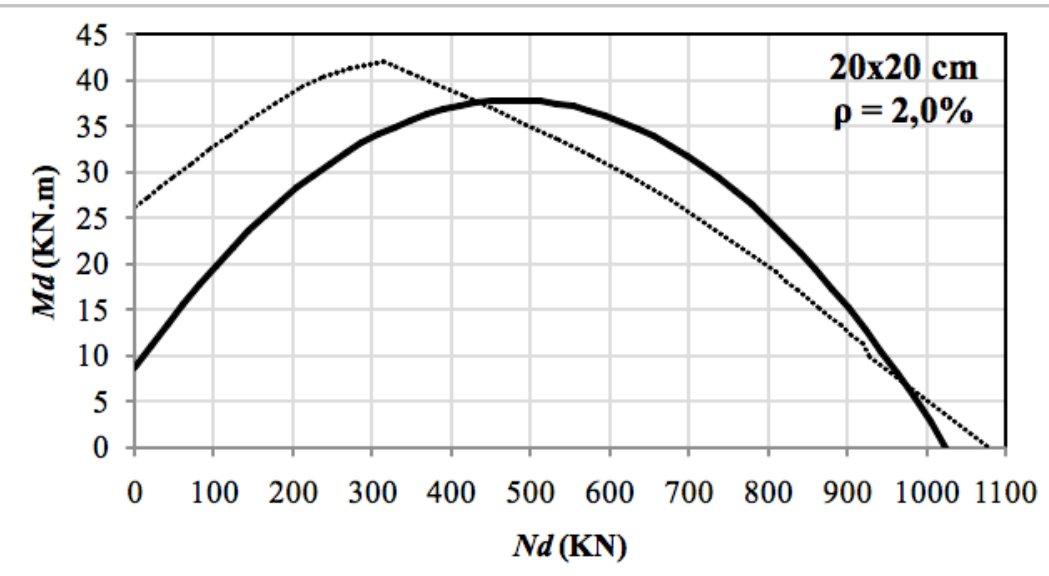

........ Diagrama Clássico (NBR6118) - Diagrama aproximado proposto 


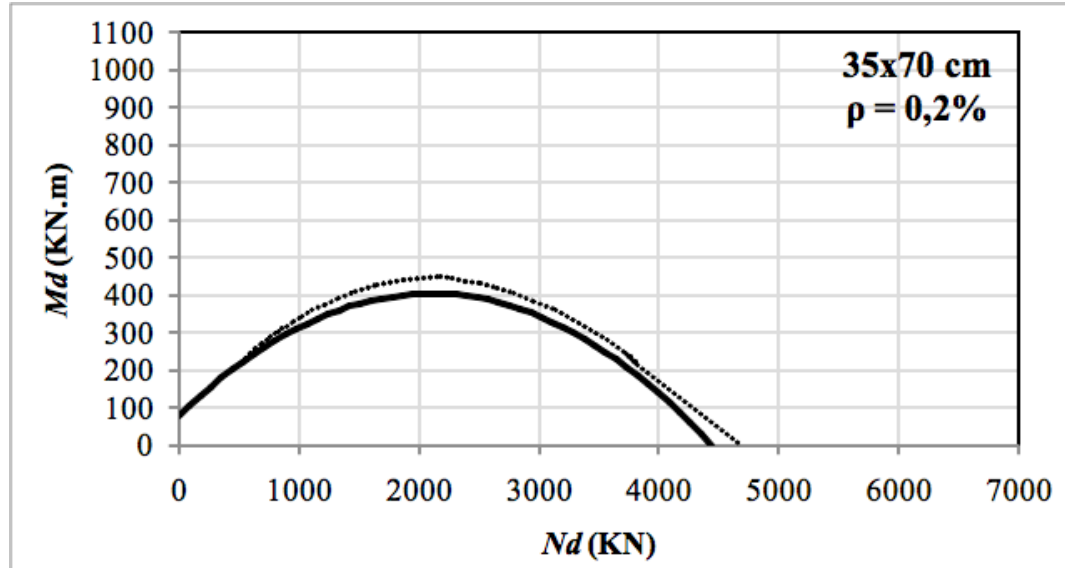

......... Diagrama Clássico (NBR6118) —Diagrama aproximado proposto

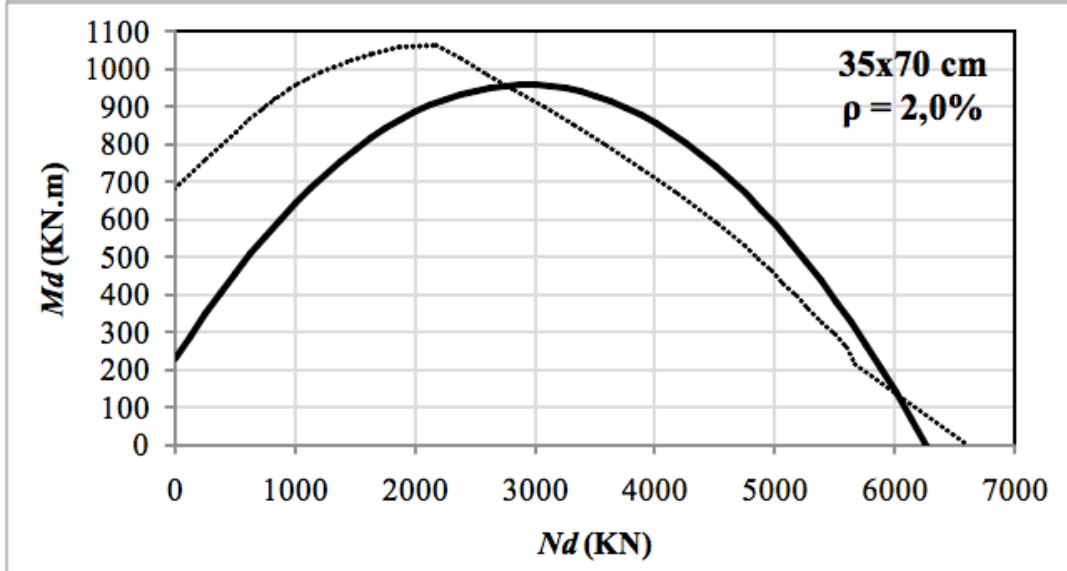

......... Diagrama Clássico (NBR6118) —Diagrama aproximado proposto

Nas construções destes diagramas exemplificadores da figura 3 foram considerados pilares de 20x20 cm de dimensão bruta e pilares de $35 \times 70$ $\mathrm{cm}$ com momento aplicado em relação à maior inércia. Foram consideradas taxa de armadura mínima de $0,8 \%$ para o pilar 20x20, sendo isto equivalente à duas barras de $10.0 \mathrm{~mm}$ em cada extremidade; e 0,2\% para o pilar 35x70, sendo isto equivalente a duas barras de $12.5 \mathrm{~mm}$ em cada extremidade. Por outro lado, foi considerada uma armadura máxima funcional. Isto é, de maneira que a taxa de armadura máxima definida pela norma (NBR6118,2003) é de 8,0\% na região de emendas, onde geralmente tem-se a duplicação da área de aço devido à comum utilização das emendas por trespasse, considerou-se que a taxa de armadura máxima normal seria de 4,0\% no total. Para levar em conta que o pilar pode estar submetido a uma flexão obliqua reta, diminuiu-se o limite então para 2,0\%.

Observa-se na figura 3 que o diagrama de interação aproximado proposto (Equação 11), nos casos analisados de taxa de armadura mínima de pilares, demonstrou estar bastante próximo ao diagrama clássico obtido por programação estruturada em algoritmo. Contudo, em taxas mais elevadas de taxa de armadura, como $2,0 \%$ por exemplo, observou-se que a função proposta para o diagrama não se aproxima tanto e até extrapola os limites que o diagrama clássico delimita. Por esta imprecisão, deve-se dizer que este método aproximado por um polinômio quadrático, fornecendo assim a relação entre os esforços atuantes e resistentes de um pilar, deve ser utilizado apenas em casos de baixas taxas de armadura ou para situações de pré-dimensionamento. Uma vez que o pórtico tridimensional parametrizado é completamente mod- 
ular, pode-se analisar um pórtico interno 2D que represente cada direção do plano da planta da edificação. A figura 4 ilustra este pórtico bidimensional parametrizado que foi considerado para a formulação das equações de pré-dimensionamento do pilar.

Figura 4 logia do pórtico parametrizado

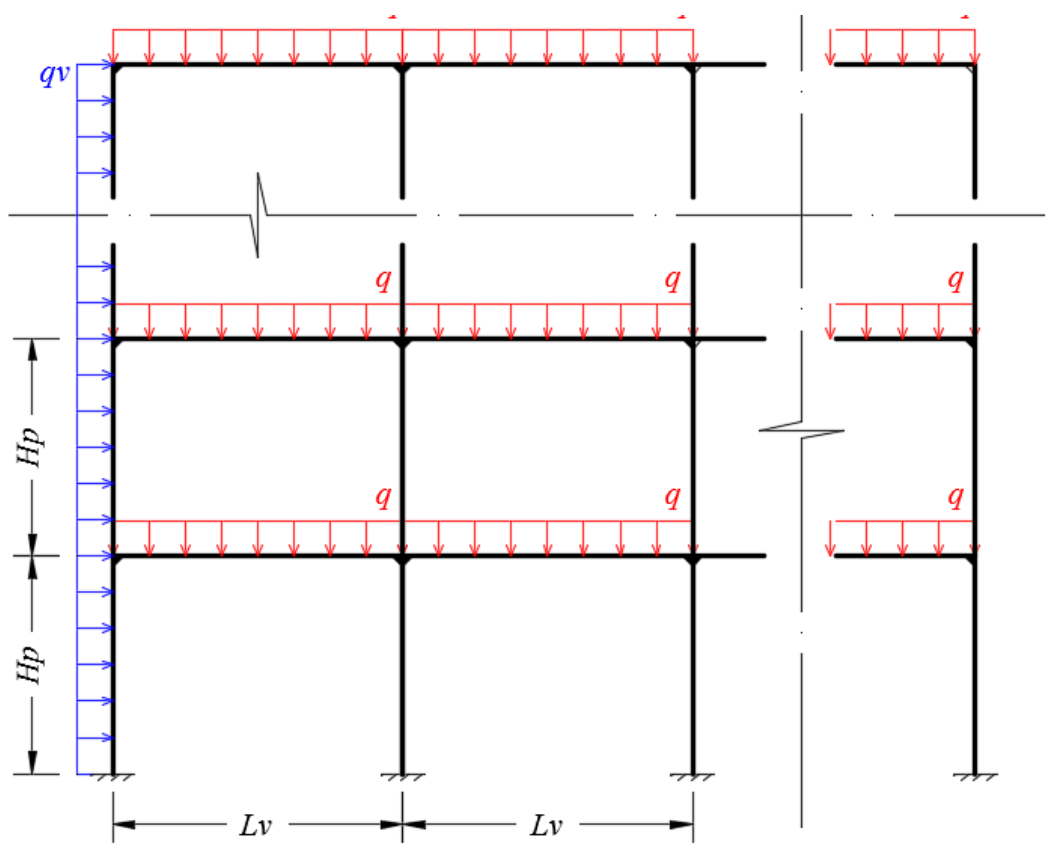

Sendo assim, considerando-se a equação 11 e respostas analíticas para 0 momento fletor e esforço normal de projeto para o pilar (HIBBELER,2012), levando em conta tanto as ações gravitacionais quanto as do vento, obtém-se a expressão paramétrica para o pilar de um pórtico segundo a condição limite de capacidade de carga. Esta expressão, dada pela equação 17, fornece 0 número máximo de pavimentos NPAV em função da carga do vento no pórtico qv em KN/m; número de quadros do pórtico nPOR; altura entre pavimentos Hp em metros; vão da viga Lv em metros; carga gravitacional nas vigas do pórtico q em KN/m; e os parâmetros A, B e C dados pelas equações de 12 a 14.

$$
\begin{aligned}
& {\left[\frac{0,04 \cdot q v^{2} \cdot n_{P O R}{ }^{2} \cdot H p^{4} \cdot A}{L v^{2} \cdot\left(n_{P O R}{ }^{2}-2 \cdot n_{P O R}+2\right)^{2}}\right] \cdot N_{P A V}{ }^{4}+\left[\frac{-0,28 \cdot q v \cdot q \cdot n_{P O R} \cdot H p^{2} \cdot A}{L v \cdot\left(n_{P O R}{ }^{2}-2 \cdot n_{P O R}+2\right)}\right] \cdot N_{P A V}{ }^{3}+} \\
& {\left[1,96 \cdot L v^{2} \cdot q^{2} \cdot A-\frac{0,20 \cdot q v \cdot n_{P O R} \cdot H p^{2} \cdot B+0,0014 \cdot A \cdot h p \cdot h p \cdot H p^{3} \cdot q v \cdot n_{P O R}}{L v \cdot\left(2 \cdot n_{P O R}{ }^{2}-2 \cdot n_{P O R}+2\right)}\right] \cdot N_{P A V}{ }^{2}+} \\
& {\left[\frac{0,40 \cdot q v \cdot H p^{2}}{\left(n_{P O R}+1\right)}-1,40 \cdot L v \cdot q \cdot B\right] \cdot N_{P A V}+} \\
& {\left[b p \cdot h p \cdot H p \cdot(0,00001225 \cdot A \cdot H p-0,0035 \cdot B)+0,0583 \cdot q \cdot L v^{2}-C\right] \leq 0}
\end{aligned}
$$

A carga linear do vento $\mathrm{q}_{\mathrm{v}}$ nos pórticos bidimensionais em análise foi obtida pelo produto da carga de vento na fachada da estrutura da edificação (NBR6123,1988) pela faixa de influência de cada pórtico bidirecional na direção considerada.

A solução da inequação 17 fornece o número máximo de pavimentos NPAV para um determinado conjunto de parâmetros de entrada, segundo a condição de capacidade resistente à flexo-compressão do pilar.

De forma análoga, aplicando a desigualdade entre o esforço cortante atuante de projeto no pilar e o cortante resistente da biela comprimida, obtém-se a expressão que fornece o número máximo de pavimentos que a seção dada para o pilar suporta (Eq. 18), segundo a condição do esforço cortante. 
$N_{P A V} \leq \frac{n_{P O R}+1}{0,80 \cdot q v \cdot H p} \cdot\left[\left(192,8-0,7714 \cdot f_{c k}\right) \cdot f_{c k} \cdot b_{P} \cdot h_{P}-1,40 \cdot \frac{q \cdot L v}{20}\right]$

Outra condição limite do número de pavimentos considerada nesta parametrização foi o deslocamento horizontal máximo no topo do edifício. Para isto, considerou-se o limite máximo de deslocamento lateral da norma (NBR6118,2003) e a solução analítica para o deslocamento lateral de um pórtico de nós rígidos de Schultz (1992), obtendo então a expressão paramétrica que fornece o número máximo de pavimentos suportado pelo pilar dado, segundo a condição limite do deslocamento no topo da edificação (Eq. 19).

$$
N_{P A V} \leq \frac{48 \cdot K_{P} \cdot\left(n_{P O R}+1\right) \cdot\left[103 \cdot K_{P} \cdot\left(n_{P O R}+1\right)+1760 \cdot K_{V} \cdot n_{P O R}\right]}{1795200 \cdot q v \cdot H p^{2} \cdot\left[K_{P}+n_{P O R} \cdot\left(K_{P}+K_{V}\right)\right]}-1
$$

$$
\left\{\begin{array}{l}
K_{P}=\frac{E_{C S} \cdot I_{P}}{H p} \\
K_{V}=\frac{E_{C S} \cdot I_{V}}{L v}
\end{array}\right.
$$

Na expressão 20 tem-se as rigidezes do pilar $\mathrm{K}_{\mathrm{p}}$ e da viga $\mathrm{K}_{\mathrm{v}}$ que compõem o pórtico bidimensional em análise, sendo estes calculados em função do módulo elástico secante do concreto $\mathrm{E}_{\mathrm{CS}} \mathrm{em} \mathrm{KN} / \mathrm{m}^{2}$ e do momento de inércia do pilar $\mathrm{I}_{\mathrm{p}}$ e da viga $\mathrm{I}_{\mathrm{v}}$, respectivamente dados em $\mathrm{m}_{4}$.

Outro equacionamento necessário para a parametrização dos pilares desta estrutura porticada de múltiplos pavimentos é o que limita o número de pavimentos segundo a condição limite da estabilidade global. Tendo o parâmetro $\gamma_{\mathrm{z}}$ como avaliador da estabilidade global de uma edificação porticada segundo a NBR6118 (2003), considerou-se este parâmetro limitado ao valor de 1,10. Utilizando expressões analíticas para calcular os pesos verticais por área de influência e os deslocamentos laterais (SCHULTZ,1992), obteve-se a expressão que fornece o número máximo de pavimentos segundo a condição da estabilidade global do pórtico (Eq. 21). $\left[1,40 \cdot N_{K} \cdot K \delta\right] \cdot N_{P A V}^{2}+\left[2,80 \cdot N_{K} \cdot K \delta-0,073 \cdot q v \cdot H p^{2}\right] N_{P A V}+\left[1,40 \cdot N_{K} \cdot K \delta\right] \leq 0$

$$
K \delta=\frac{3520 \cdot q v \cdot \mathrm{Hp}^{3} \cdot\left[K_{P}+n_{P O R} \cdot\left(K_{P}+K_{V}\right)\right]}{48 \cdot K_{P} \cdot\left(n_{P O R}+1\right) \cdot\left[103 \cdot K_{P} \cdot\left(n_{P O R}+1\right)+1760 \cdot K_{V} \cdot n_{P O R}\right]}
$$

Para cada pórtico bidimensional representativo para cada direção da ação do vento foi gerada uma equação de pré-dimensionamento dos pilares, de acordo com a disposição das seções transversais do mesmo. Nas equações de 17,18,19 e 21, o menor valor obtido para o número de pavimentos $\mathrm{N}_{\mathrm{PAV}}$ representa o número máximo de pavimentos relativo à seção dada para o pilar.

\section{Programação paramétrica de edifícios porticados em concreto}

De posse do equacionamento que relaciona os parâmetros que envolvem o pré-dimensionamento da estrutura de pórtico tridimensional proposta, elaborou-se um algoritmo generativo da geometria desta estrutura. A figura 5 ilustra o esquema do algoritmo proposto que acopla as equações de pré-dimensionamento à geração geométrica das lajes, vigas e pilares do pórtico 


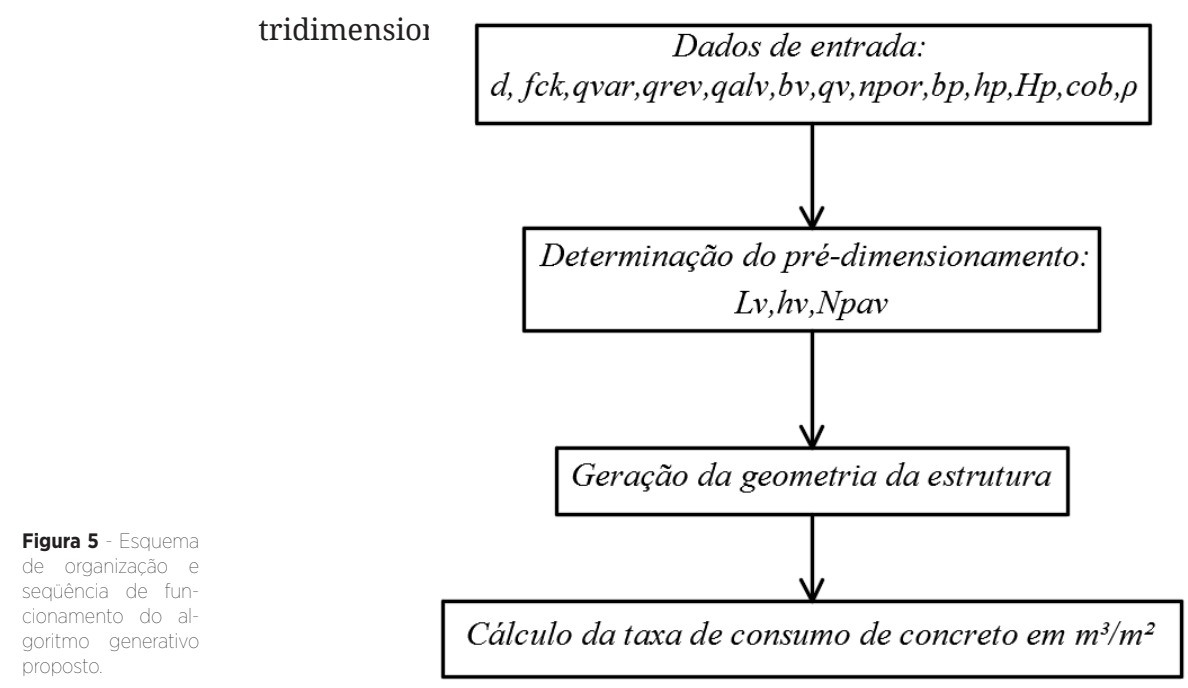

tridimensio

Determinação do pré-dimensionamento:

Cálculo da taxa de consumo de concreto em $\mathrm{m}^{3} / \mathrm{m}^{2}$

Implementando o algoritmo na seqüência esquemática ilustrada pela figura 5 no ambiente do Grasshopper, obtém-se o algoritmo generativo de estruturas porticadas em concreto armado com pré-dimensionamento automático. Este algoritmo generativo é composto de blocos de resoluções da implementação das equações de pré-dimensionamento propostas e de blocos de geraçã̃o da geometria tridimensional da estrutura, resultando na geometria no ambiente do Rhinoceros. Esta geometria gerada pode ser utilizada tanto como resultado em tempo real de uma concepção estrutural quanto como instrumento didático no ensino de estruturas porticadas de múltiplos pavimentos em concreto armado.

Na figura 6 observa-se a visão geral do algoritmo generativo proposto implementado no ambiente do Grasshopper. Verifica-se em tons de verde (A, B, C e D) e azul (E, F, G e H) os blocos do código onde são definidos os parâmetros de entrada e obtidos os valores do vão do módulo da unidade básica, altura da viga e número máximo de pavimentos do pórtico. Em tons de vermelho (I) estão os blocos do código que definem a geometria tridimensional a ser obtida no ambiente do Rhinoceros em tempo real, onde o bloco em laranja (J) é responsável por replicar os elementos do sistema, gerando a estrutura como um todo. Em lilás (K) está o bloco do código que calcula a taxa de consumo de concreto da estrutura da edificação de acordo com os parâmetros de entrada definidos.

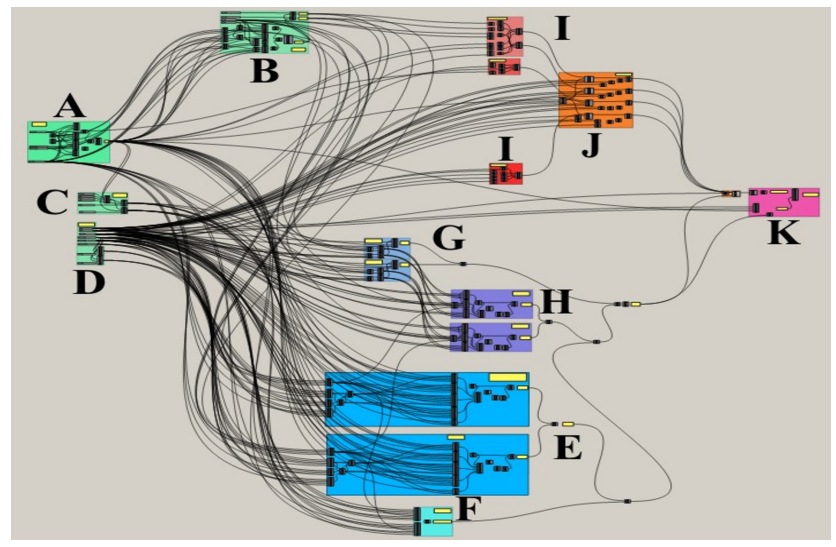

Observa-se na figura 6 que os blocos em tons de azul consistem nos cálculos dos pórticos nas duas direções em planta, portanto contido em pares.

Nas figuras de 7 a 17 estão ilustrados com maiores detalhes cada bloco de cálculo do código deste algoritmo generativo, descritos na seqüência alfabética de A a K. 


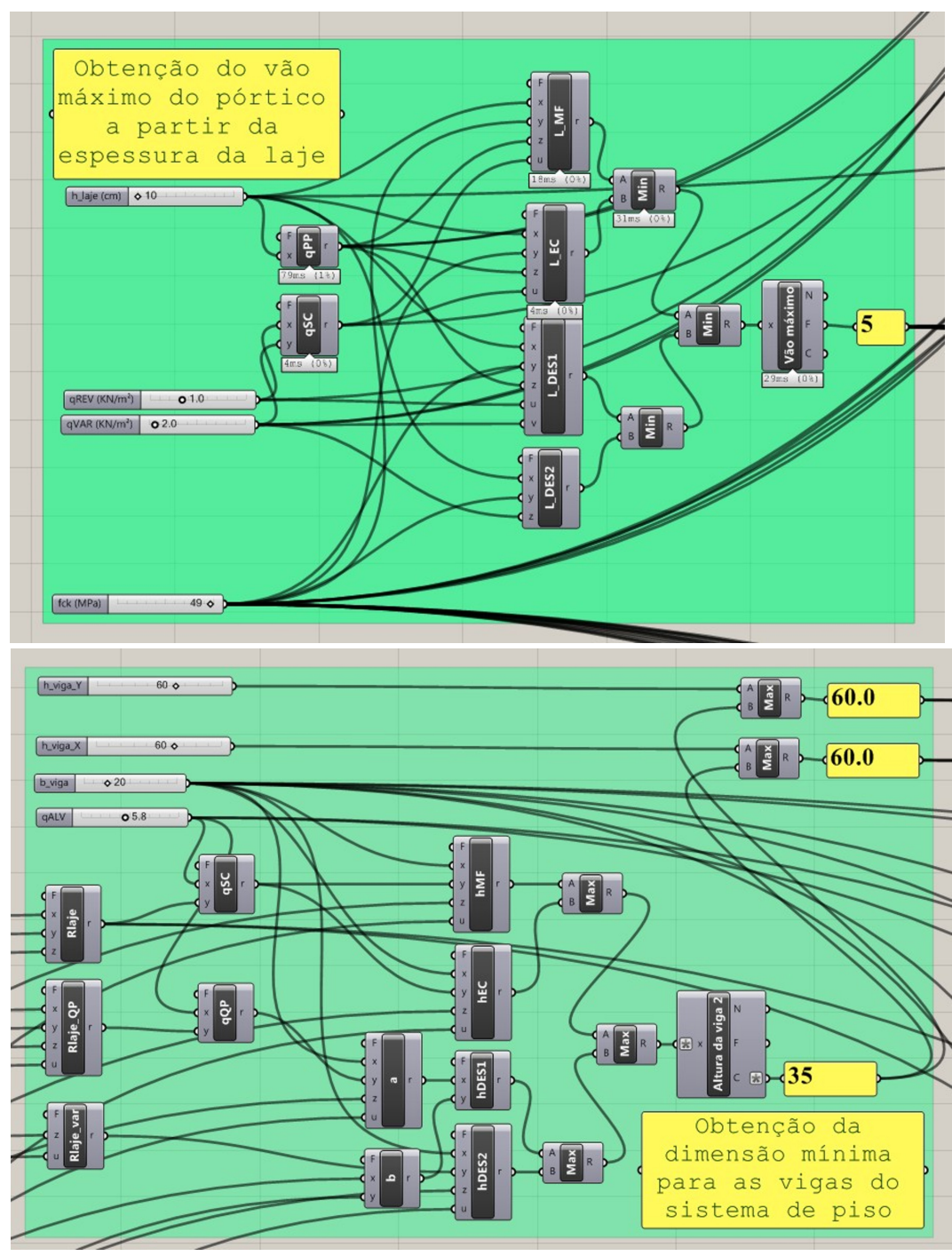

Figura 7 - Bloco $A$

do código contendo parâmetros de entrada e pré-dimensionamento da laje.

Figura 8 - Bloco B do código contendo parâmetros de entrada e pré-dimensionamento da viga.

$\mathrm{Na}$ figura 7 estão acopladas as equações de pré-dimensionamento do vão máximo da laje (Equações de 1 a 4) em função da espessura da laje, resistência característica do concreto e nível de cargas sobre a laje. Na figura 8 observa-se o bloco que define as espessuras das vigas (Equações de 5 a 10) dadas a partir do vão definido para o módulo da unidade básica, tendo a opção de se considerar vigas com alturas maiores para auxílio na rigidez lateral do edifício, caso seja necessário.

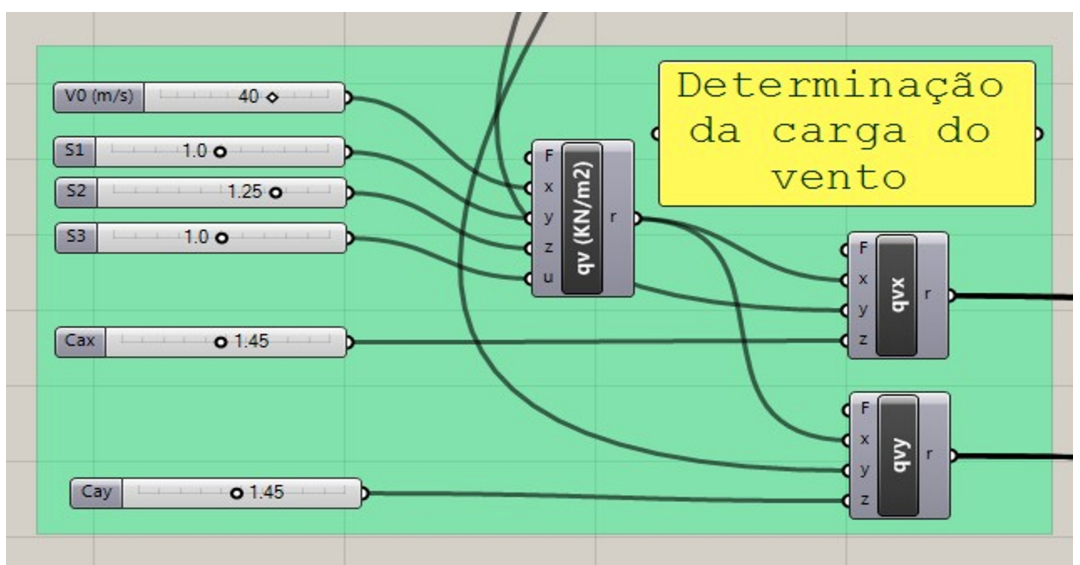


Figura $10-$ Bloco $D$ do código contendo parâmetros de entrada dos pilares.

Figura 11 - Bloco $E$ do codigo contendo o núme- máximo de pavimentos: condição da capacdade à flexo-compressão.

Figura 12 - Bloco $F$ do código contendo número máximo de pavimentos condição da capacidade ao esforço cortante

$\mathrm{Na}$ figura 9 observa-se o bloco de cálculo da carga de vento com os parâmetros de acordo com a norma brasileira vigente (NBR6123,1988). Estes valores, dependentes do contexto em que a edificação se encontra em termos de características topográficas e dimensões globais da edificação, devem ser utilizados de acordo com as tabelas e ábacos da referida norma de cálculo de carga de vento.

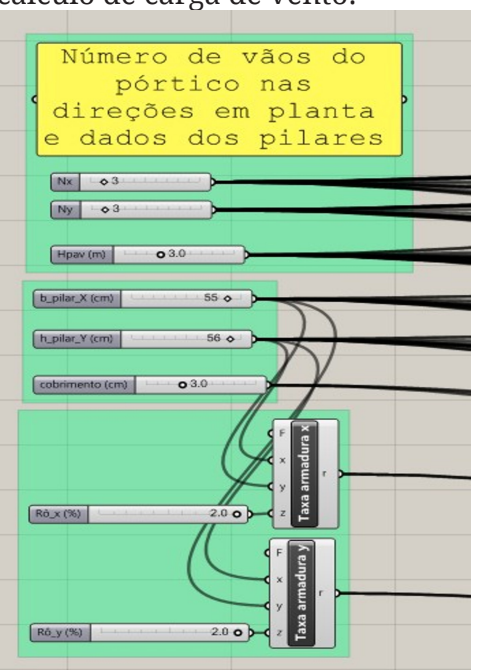

Na figura 10 observa-se os dados de entrada para definição da replicação da unidade básica porticada e a definição da seção transversal dos pilares e sua taxa de armadura para as duas formações de pórticos nas duas direções em planta.

Na figura 11 tem-se o bloco de cálculo do número máximo de pavimentos que o pilar escolhido suporta de acordo com sua capacidade de resistência à flexo-compressão. Isto é obtido, para cada direção em planta, aplicando-se o método simplificado proposto de diagrama de interação entre $\mathrm{Nd}$ e $\mathrm{Md}$ (Equações de 11 a 16) sobre a forma paramétrica de pré-dimensionamento utilizando soluções analíticas para determinação dos esforços de projeto do pilar mais solicitado (Eq. 17).

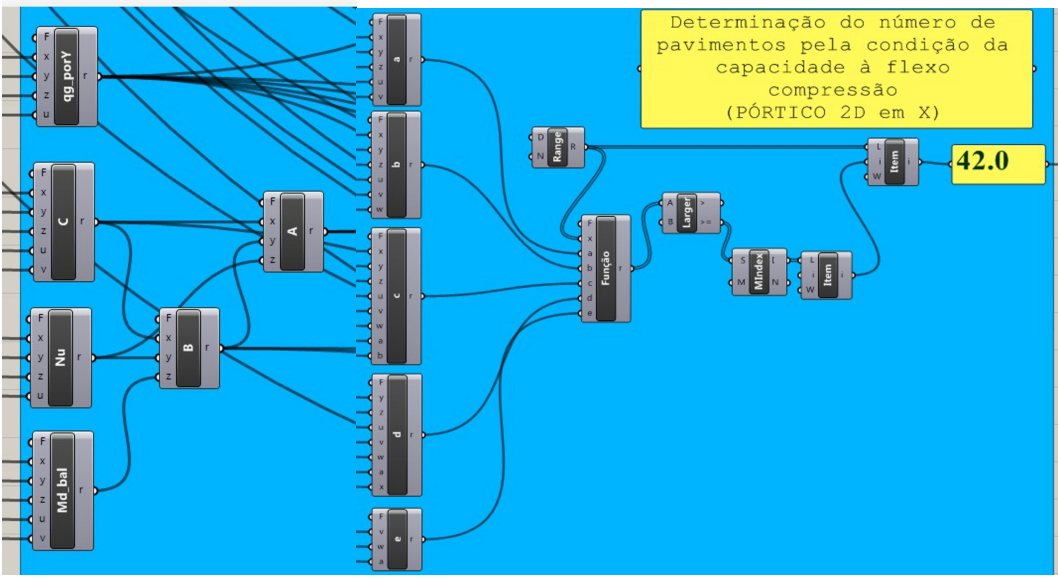

Na figura 12 tem-se um pequeno bloco que define o número de pavimentos que os pilares escolhidos suportam segundo a condição do esmagamento da biela comprimida devido ao esforço cortante (Eq. 18).

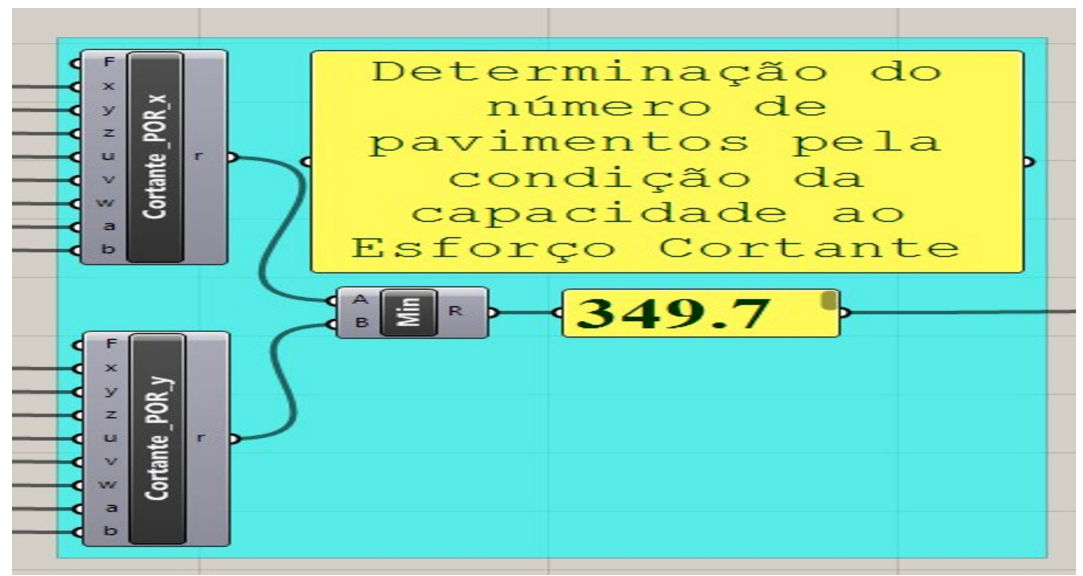




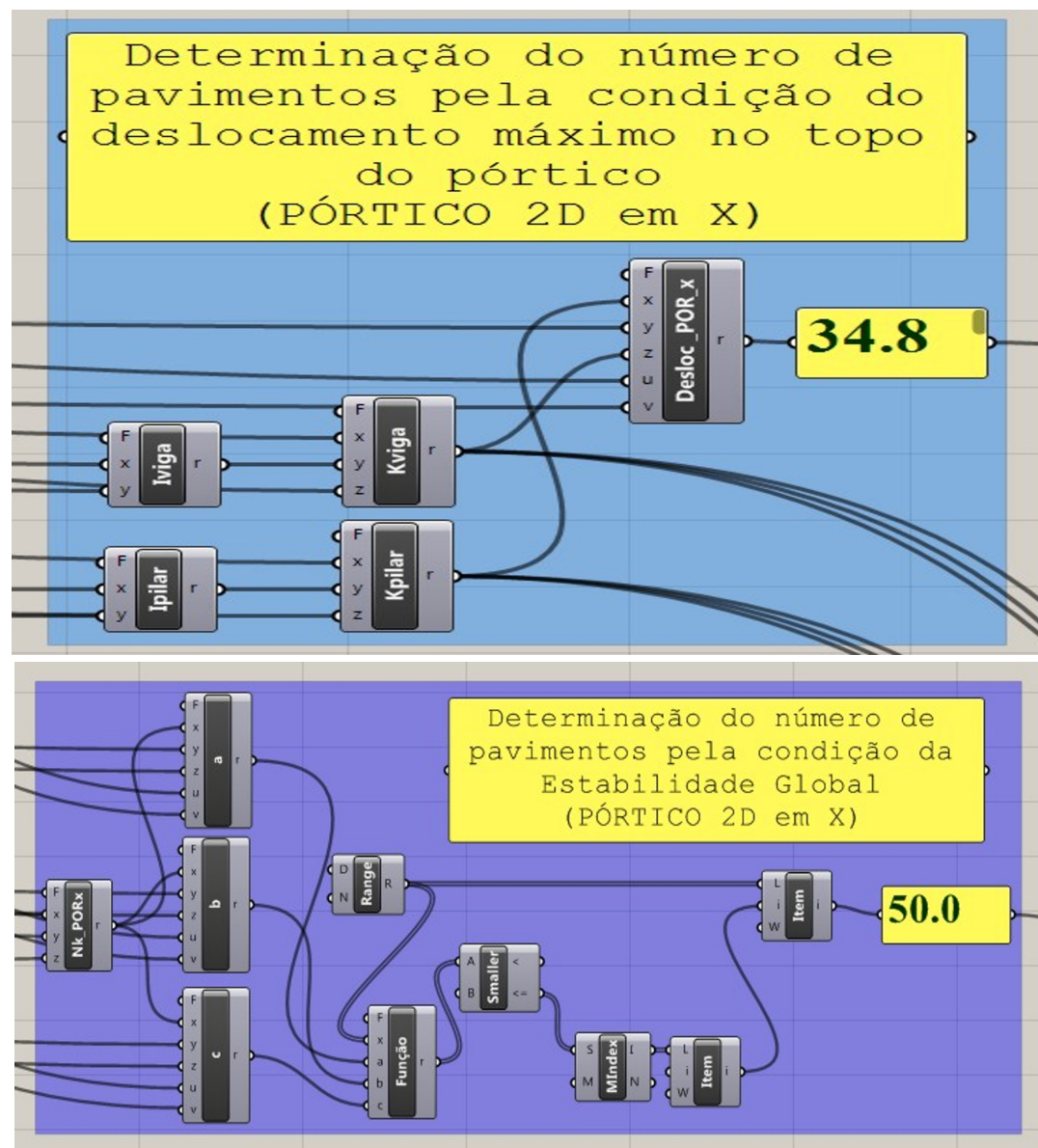

Figura 13 - Bloco $G$ do código contendo número máximo de pavimentos: condição do deslocamento máximo no topo do edificio.

Figura 14 - Bloco $H$ do código contendo o numero máximo de da estabilidade global.

Na figura 13 observa-se o bloco de cálculo do número de pavimentos que o pilar escolhido suporta de acordo com a condição limite da deslocabilidade lateral no topo do pórtico devido à carga do vento, obtido a partir da aplicação da expressão 19. Em relação à estabilidade global, isto é, segundo a limitação do parâmetro $\gamma \mathrm{Z}$, a figura 14 ilustra a implementação da resolução da inequação dada pela expressão 21 .

Após a implementação de todos os cálculos de pré-dimensionamento, acoplou-se a geração parametrizada das geometrias das lajes, vigas e pilares, como ilustram os blocos de comandos do código proposto, ilustrado pela figura 15.
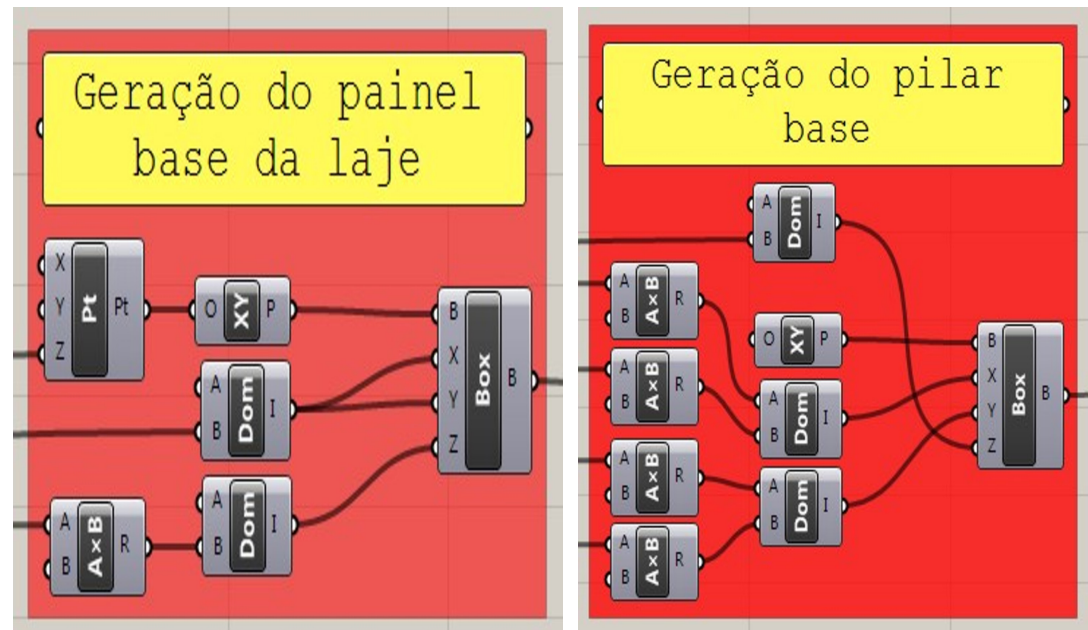


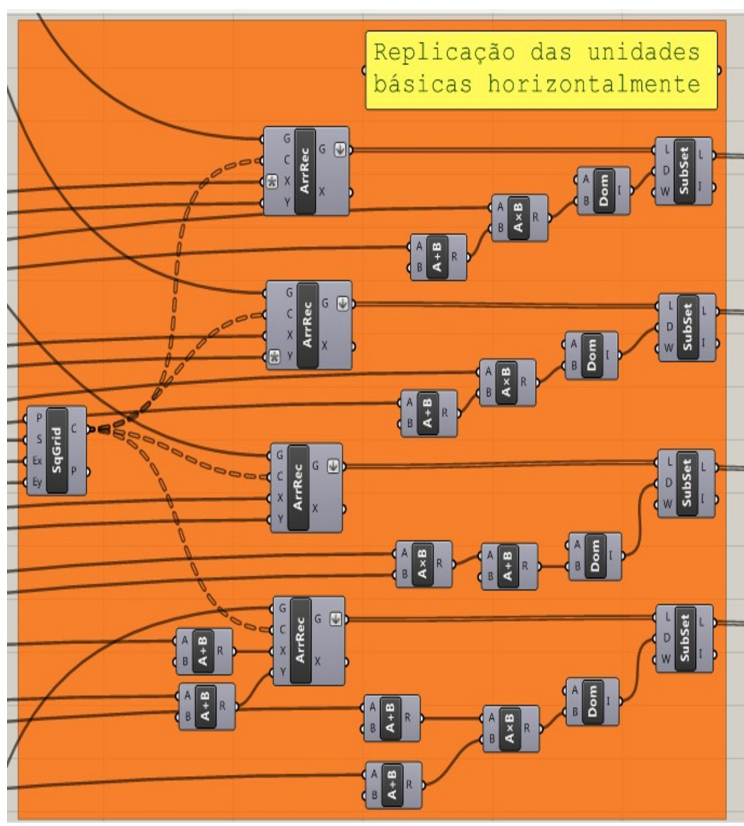

Figura 16 - Bloco J do códi go contendo a replicação da geometria: replicaçăo das unidades básicas horizontalmente
Figura 17 - Blocos $k$ do código contendo a replicação vertical da estrutura $e$ cálculo da taxa de consumo de concreto
Na figura 15 observa-se os blocos de comandos do algoritmo generativo que geram as peças base do sistema estrutural e posteriormente são replicados (Figura 16). Esta replicação deu-se pela entrada de valores do número de replicações da unidade básica na horizontal, enquanto na vertical pelo número máximo de pavimentos.

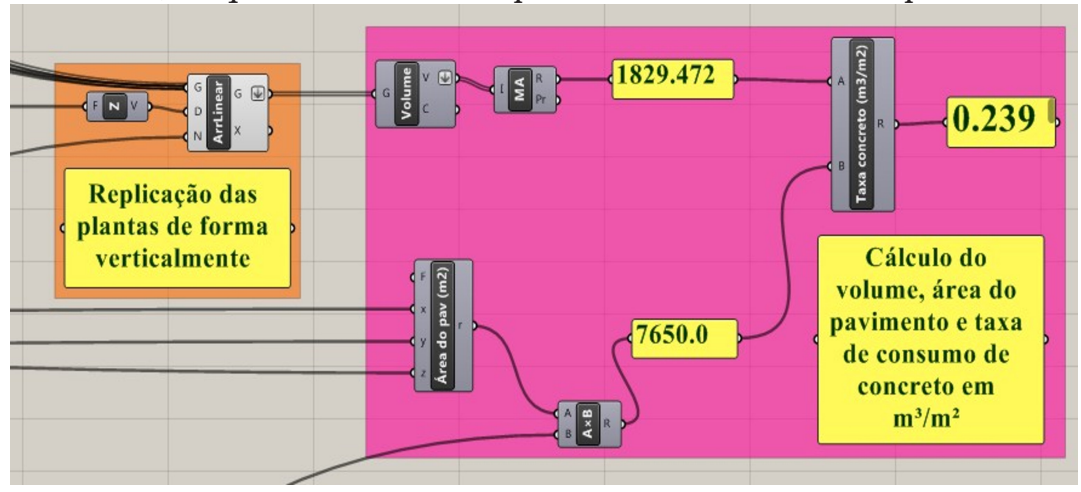

A figura 17 ilustra o último bloco de instruções do algoritmo, gerando a replicação vertical e a contabilização de áreas, volumes e a taxa de consumo de concreto, também conhecida como espessura fictícia.

Ao variar os valores dos parâmetros de entrada deste algoritmo paramétrico, obtém-se em tempo real o modelo tridimensional da estrutura da edificação (Fig. 18) no ambiente do Rhinoceros. Esta obtenção em tempo real da proporção entre as macro e micro dimensões deste sistema estrutural oferece ao projetista simultaneamente o impacto da geometria da estrutura no layout arquitetônico e uma estimativa do consumo de concreto através da espessura fictícia, fornecendo também de imediato uma estimativa do impacto econômico e ambiental. 

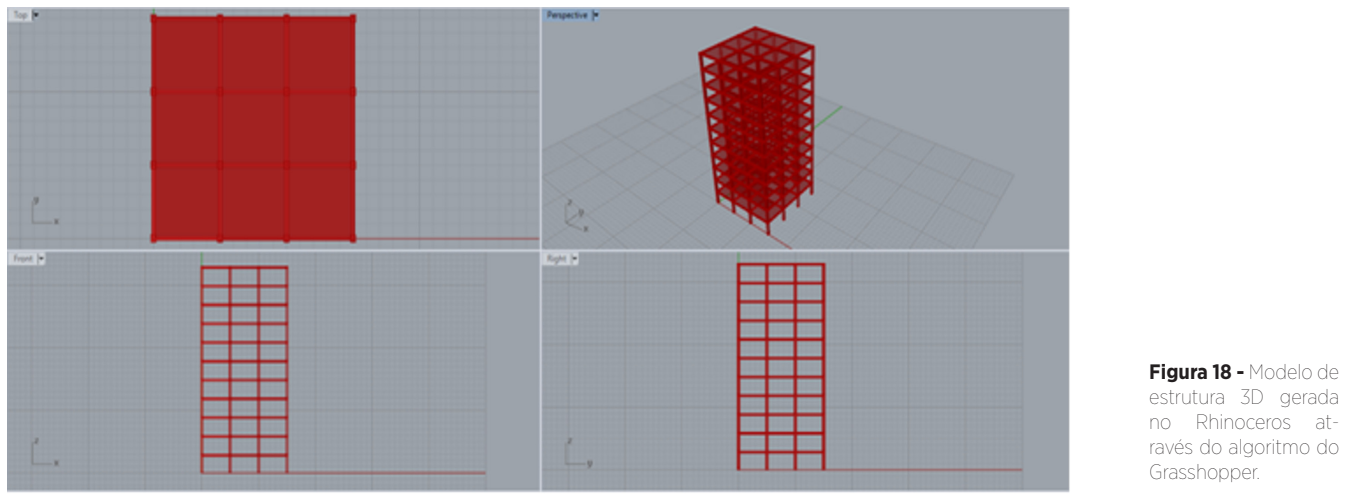

\section{Validação de algoritmo}

Com o intuito de verificar se o modelo de estrutura 3D gerado pelo algoritmo proposto efetivamente gera um conjunto que irá satisfazer as condições dos Estados Limites, foram aplicados testes em modelos gerados pelo algoritmo proposto. Em dois casos de modelos gerados com parâmetros originados de diferentes premissas, foi utilizado o sistema TQS para efetuar o dimensionamento das armaduras e verificações dos Estados Limites. 0 sistema TQS é um software BIM que realiza a análise e dimensionamento de armaduras de estruturas porticadas em concreto armado, baseado na norma NBR6118 (2003).

Foram realizadas simulações no sistema TQS de duas edificações geradas pelo algoritmo proposto, onde cujos parâmetros de entrada que foram fixados estão organizados na tabela 1. Os demais parâmetros de entrada foram obtidos através do processo de otimização para a maximização do número de pavimentos. O Grasshopper já possui uma interface de otimização funcional baseada em algoritmos genéticos, otimizando o resultado de um componente funcional do algoritmo em função da variação de um parâmetro de entrada.

Observa-se na tabela 2 que as taxas de consumo de concreto para os dois edifícios investigados estão na ordem de grandeza relatada por Oliveira et al. (2013) e Pereira et al. (2013). Verifica-se que com o aumento do vão do sistema de piso aumenta-se a demanda por maior capaci-

\begin{tabular}{|c|c|c|c|c|c|c|c|c|c|c|}
\hline & $\mathrm{d}(\mathrm{cm})$ & $\mathrm{Lv}(\mathrm{m})$ & $\mathrm{f}_{\mathrm{cs}}(\mathrm{MPa})$ & $\begin{array}{c}q_{\mathrm{VAR}} \\
\left(\mathrm{KN} / \mathrm{m}^{2}\right)\end{array}$ & $\begin{array}{c}q_{\mathrm{REV}} \\
\left(\mathrm{KN} / \mathrm{m}^{2}\right)\end{array}$ & $\begin{array}{c}q_{A L V} \\
(\mathrm{KN} / \mathrm{m})\end{array}$ & bv $(\mathrm{cm})$ & $\mathrm{n}_{\mathrm{POR} X \mathrm{X}}$ & $\mathrm{n}_{\mathrm{POR}} \mathrm{Y}$ & $\begin{array}{c}\text { bp e hp } \\
(\mathrm{cm})\end{array}$ \\
\hline Edificio A & 10 & 5 & $20 \times 50$ & 2 & 1 & 5,8 & $15 \times 50$ & 9 & 9 & $20 \times 55$ \\
\hline Edificio B & 20 & 8 & $20 \times 50$ & 9 & 1 & 5,8 & $15 \times 50$ & 4 & 2 & $20 \times 90$ \\
\hline
\end{tabular}

Tabela 1 - Valores fixados e faixas de valores dos parâmetros de entrada da geração dos exemplos.

Nos dois casos, foi considerada uma distância entre pavimentos de 3,0 $\mathrm{m}$, cobrimento de armadura de $3,0 \mathrm{~cm}$ e taxa de armadura de $2 \%$ para cada direção de flexão do pilar. Foi considerado para o cálculo da força do vento uma velocidade básica de $40 \mathrm{~m} / \mathrm{s}$, parâmetros da velocidade características S1=S3=1 e parâmetro S2 e coeficiente de arrasto de acordo com as dimensões finais do edifício.

Com as espessuras de $10 \mathrm{~cm}$ e $20 \mathrm{~cm}$ para a laje maciça, obteve-se respectivamente 5,0 m e 9,0 m para os vãos dos sistemas de piso, sendo também estes os espaçamentos entre os pilares. Após o processo de otimização por algoritmo genético dos parâmetros que foram considerados variáveis (fck, bv, hv, bp e hp), obteve-se o valor dos parâmetros variáveis de modo a maximizar o número de pavimentos, sendo os resultados apresentados na tabela 2.

\begin{tabular}{|l|c|c|c|c|c|c|c|c|c|c|}
\hline & $\mathrm{f}_{\mathrm{cs}}(\mathrm{MPa})$ & $\mathrm{bv}(\mathrm{cm})$ & $\mathrm{hv}(\mathrm{cm})$ & $\mathrm{bp}(\mathrm{cm})$ & $\mathrm{hp}(\mathrm{cm})$ & $\mathrm{N}_{\text {PAV }}$ & $\begin{array}{c}\text { Espessur } \\
\text { a ficticia } \\
\left(\mathrm{m}^{3} / \mathrm{m}^{2}\right)\end{array}$ & $\begin{array}{c}\mathrm{A}_{\mathrm{PAV}} \\
\left(\mathrm{m}^{2}\right)\end{array}$ & $\begin{array}{c}\sum \mathrm{A}_{\text {PAV }} \\
\left(\mathrm{m}^{2}\right)\end{array}$ & $\begin{array}{c}\mathrm{V}_{\text {CON }} \\
\left(\mathrm{m}^{3}\right)\end{array}$ \\
\hline Edificio A & 50 & 20 & 35 & 50 & 50 & 10 & 0,26 & 225 & 2250 & 577 \\
\hline Edificio B & 30 & 30 & 70 & 50 & 90 & 9 & 0,32 & 512 & 4608 & 1479 \\
\hline
\end{tabular}


dade dos pilares, tendendo a atingir um menor número de pavimentos.

$\mathrm{Na}$ figura 19 são apresentadas as imagens em perspectiva destes dois modelos de estrutura porticada que estão sendo investigadas..

De posse destes dois modelos de edificação pré-dimensionados, efetuou-se a verificação e dimensionamento das armaduras no sistema TQS. Foi obtido como resposta a total verificação das estruturas aos Estados Limites e a não apresentação de restrições no dimensionamento das armaduras. Na tabela 3 sãoapresentadososresultadosobtidosnoTQSpara os dois exemplos em estudo.
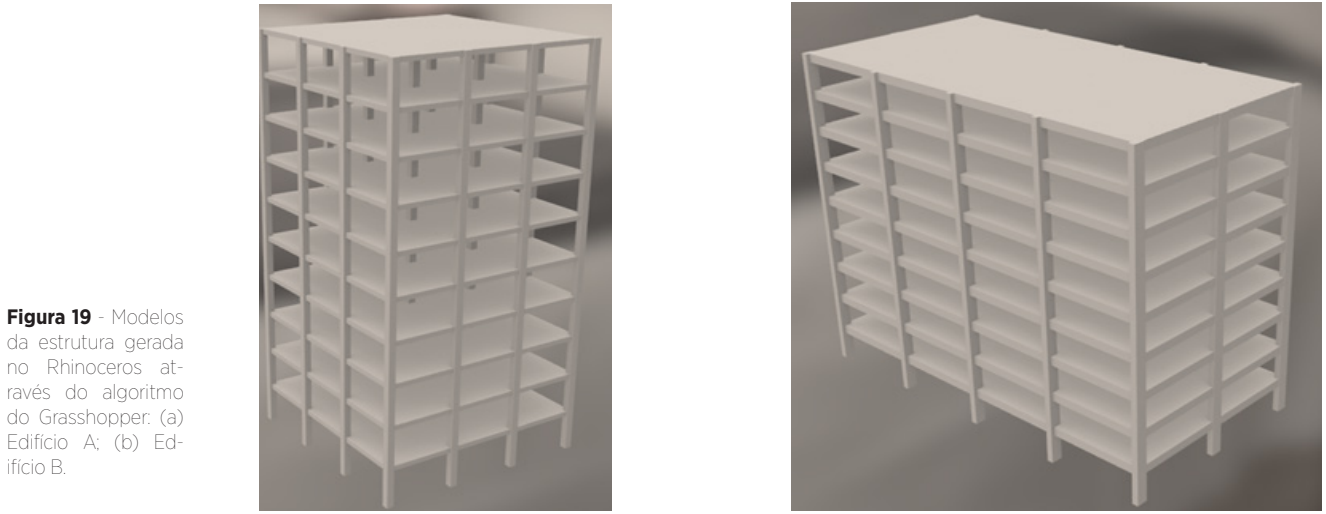

\begin{tabular}{|l|c|c|c|c|}
\hline & $\begin{array}{c}\text { Taxa de } \\
\text { concreto } \\
\left(\mathrm{m}^{2} / \mathrm{m}^{2}\right)\end{array}$ & $\begin{array}{c}\text { Taxa de aço } \\
\left(\mathrm{kg} / \mathrm{m}^{2}\right)\end{array}$ & $\begin{array}{c}\text { Relação } \\
\text { aço/concret } \\
\text { o }\left(\mathrm{kg} / \mathrm{m}^{2}\right)\end{array}$ & $\begin{array}{c}\text { Taxa de } \\
\text { formas } \\
\left(\mathrm{m}^{2} / \mathrm{m}^{2}\right)\end{array}$ \\
\hline Edificio A & $\mathbf{0 , 1 8}$ & $\mathbf{1 9 , 6 4}$ & $\mathbf{1 0 9 , 7 4}$ & $\mathbf{1 , 6 5}$ \\
\hline Edificio B & $\mathbf{0 , 2}$ & $\mathbf{5 , 3 7}$ & $\mathbf{7}, 57$ & $\mathbf{1 , 5 6}$ \\
\hline
\end{tabular}

Observa-se na tabela 3 que as taxas finais do consumo de concreto, obtidas pelo TQS se demonstraram inferiores (-30\% e -12\%) das estimadas pelo algoritmo generativo proposto. As taxas de armadura obtidas são compatíveis com os níveis relatados por Oliveira et al. (2013) e Pereira et al. (2013).

\section{DISCUSSÃO E CONCLUSÕES}

Este artigo propôs o uso de expressões matemáticas de pré-dimensionamento para a parametrização de pórtico tridimensional com lajes maciças bidirecionais, vigas e pilares. Posteriormente, foram acopladas estas expressões a um algoritmo generativo paramétrico de modelo tridimensional de uma estrutura porticada de múltiplos pavimentos. Foram gerados dois modelos otimizados utilizando algoritmos genéticos, os quais foram validados através do sistema TQS. Observa-se, através da confirmação do sistema TQS que os modelos gerados pelo algoritmo paramétrico proposto satisfizeram as condições dos Estados Limites e apresentaram taxas de consumo de materiais compatíveis com o relatado pela literatura.

$\mathrm{O}$ algoritmo generativo de estruturas porticadas em concreto armado proposto demonstrou ser uma ferramenta útil na concepção otimizada deste tipo de estrutura, possibilitando a otimização de alguns parâmetros como o número de pavimentos, podendo-se também minimizar a taxa de concreto ou o volume total de concreto de modo a visar um menor impacto econômico ou ambiental. Pode-se dizer também que este algoritmo generativo paramétrico pode ser utilizado no processo de aprendizagem deste tipo de estruturas, tanto em disciplinas de projeto de arquitetura quanto de projeto de estruturas. 


\section{AGRADECIMENTOS}

$\mathrm{O}$ autor deste artigo agradece à TQS sistemas pelo apoio fundamental à pesquisa que gerou este estudo.

\section{REFERÊNCIAS}

ALLEN, E.; IANO, J. The architect's studio companion: rules of thumb for preliminary design. 3rd Ed., John Wileyand Sons, 2002.

ASSOCIAÇÃO BRASILEIRA DE NORMAS TÉCNICAS. NBR 6118: Projeto de Estruturas de concreto - Procedimento. Rio de Janeiro, 2003.

NBR 6123: Forças devido ao vento em edificações. Rio de Janeiro, 1988.

CARVALHO, R. C.; PINHEIRO, L. M. Cálculo e detalhamento de estruturas usuais de concreto armado. Volume 2. Ed. PINI, 2.ed, 2013.

CHING, F. D. K.; ONOUYE, B. S.; ZUBERBUHLER, D. Sistemas Estruturais Ilustrados: padrões sistemas e projeto. Bookman, 2010.

CORKILL, P. A. Preliminary Structural Design Charts for Architects. Architectural Science Review, 12:1, 15-20, 1969

ENGEL, H. Sistemas Estruturais. Ed. Gustavo Gili, 2001.

HIBBELER, R. C. Structural Analysis. 8th Edition, Prentice Hall, 2012.

KHABAZI, Z. Generative Algorithms using Grashopper. Morphogenesism, 2012. Disponível em: <http://www. morphogenesism.com>. Acesso em: 15 jan. 2015
KOLAREVIC, B. Architecture in the digital age: design and manufacturing New York: Spoon Press, 2003. 441p.

MACDONALD, A. J. Structural design for architecture. Architectural Press, 1998.

MOUSSAVI, F. The function of the Form. Actar editora, Barcelona, 2009.

OLIVEIRA, F. R. M.; SILVA, M. G.; GOMES, V. Indicadores de desempenho funcional, ambiental e econômico de sistemas de lajes em concreto. $\mathbf{5 5}^{\circ}$ Congresso Brasileiro do Concreto, 2013

PEREIRA, R. L.; VINHAIS, G. C.; ARAÚJO, Y. R. O. Análise de indicadores de projetos estruturais de edifícios de múltiplos pavimentos. $\mathbf{5 5}^{\circ}$ Congresso Brasileiro do Concreto, 2013.

REBELO, Y. C. P. Bases para projeto estrutural na arquitetura. Ed. Zigurate, 2. ed, 2007.

SANDAKER, B. N. On span and space: exploring structures in architecture. Ed. Routledge, 2008.

SCHULTZ, A. E. Approximating lateral stiffness of stories in elastic frames. Journal of Structural Engineering, Vol. 18, no. 1, 1992.

WIGHT,J. K.; MACGREGOR,J. G. Reinforced concrete: mechanics and design. 6a Edition, Pearson, 2012 